Old Dominion University

ODU Digital Commons

Community \& Environmental Health Faculty

Publications

Community \& Environmental Health

10-10-2019

\title{
Fetal Myocardial Performance Index in the Third Trimester of \\ Pregnancy: Feasibility and Reproducibility of Conventional Spectral Doppler versus Spectral Tissue Doppler Technique
}

\author{
Lea M. Porche \\ Elena Sinkovskaya \\ Rachel D. Seaman \\ Hadiza I. Galadima \\ Old Dominion University, hgaladim@odu.edu \\ Letty Romary
}

See next page for additional authors

Follow this and additional works at: https://digitalcommons.odu.edu/commhealth_fac_pubs

Part of the Family Medicine Commons, Maternal, Child Health and Neonatal Nursing Commons, and the Obstetrics and Gynecology Commons

\section{Original Publication Citation}

Porche, L. M., Sinkovskaya, E., Seaman, R. D., Galadima, H., Romary, L., Philips, J., \& Abuhamad, A. (2019). Fetal myocardial performance Index in the third trimester of pregnancy: Feasibility and reproducibility of conventional spectral doppler versus spectral tissue doppler technique. American Journal of Perinatology. https://doi.org/ 10.1055/s-0039-1697585

This Article is brought to you for free and open access by the Community \& Environmental Health at ODU Digital Commons. It has been accepted for inclusion in Community \& Environmental Health Faculty Publications by an authorized administrator of ODU Digital Commons. For more information, please contact digitalcommons@odu.edu. 


\section{Authors}

Lea M. Porche; Elena Sinkovskaya; Rachel D. Seaman; Hadiza I. Galadima; Letty Romary; Jennifer Philips; and Alfred Abuhamad, 


\title{
Fetal Myocardial Performance Index in the Third Trimester of Pregnancy: Feasibility and Reproducibility of Conventional Spectral Doppler versus Spectral Tissue Doppler Technique
}

\author{
Lea M. Porche, MD ${ }^{1}$ Elena Sinkovskaya, MD ${ }^{1}$ Rachel D. Seaman, MD ${ }^{1}$ Hadiza Galadima, PhD ${ }^{2}$ \\ Letty Romary, MD ${ }^{1}$ Jennifer Philips, MD ${ }^{1}$ Alfred Abuhamad, MD ${ }^{1}$
}

\footnotetext{
${ }^{1}$ Department of Obstetrics and Gynecology, Eastern Virginia Medical School, Norfolk, Virginia

2 Department of Public Health, Center for Health Analytics Discovery, Eastern Virginia Medical School, Norfolk, Virginia
}

Address for correspondence Lea M. Porche, MD, Department of Obstetrics and Gynecology, Eastern Virginia Medical School, 825 Fairfax Avenue Street 544, Norfolk, VA 23507

(e-mail: porchelm@evms.edu).

Am J Perinatol

\begin{abstract}
Keywords

- myocardial performance index

- cardiac function

- tissue Doppler

- spectral Doppler

- third trimester

Objective This study aims to compare completion rates and reproducibility of myocardial performance index (MPI) using conventional spectral Doppler versus tissue Doppler in an unselected high-risk third trimester population.

Study Design This was a prospective cross-sectional study of high-risk pregnancies at $\geq 28+0$ weeks' gestation. Conventional spectral and tissue Doppler MPI of the left ventricle (LV) and right ventricle (RV) was attempted on all patients.

Results Seventy-nine pregnancies were evaluated. LV tissue Doppler MPI was completed more frequently than LV conventional spectral Doppler MPI (63/79, 79.7\% vs. $45 / 79,55.7 \%$ ), $p$-value $<0.01$. RV tissue Doppler MPI was completed more frequently than RV conventional spectral Doppler MPI (68/79, $86 \%$ vs. $42 / 79,53.2 \%)$, p-value $<0.01$. In obese subjects $(n=50)$ LV tissue Doppler MPI was completed more frequently than LV conventional spectral Doppler MPI (37/50, $74 \%$ vs. $26 / 50,52 \%$ ), $p$-value $<0.01$. RV tissue Doppler MPI was completed more frequently than RV conventional spectral Doppler MPI (40/50, $80 \%$ vs. $25 / 50,50 \%$ ), $p$-value $<0.01$. intraclass correlation coefficient for all modalities ranged between 0.73 and 0.93 , except for LV conventional spectral Doppler intraobserver variability which was 0.22 . Conclusion Tissue Doppler had statistically higher completion rates than conventional spectral Doppler, including the obese subgroup, with evidence of strong reproducibility in the third trimester.
\end{abstract}

Many maternal and fetal conditions are known to compromise fetal cardiac function during gestation. Maternal uncontrolled diabetes, hypertensive disorders in pregnancy, fetal infections, anemia, and congenital malformations are associated with fetal cardiomyopathy. ${ }^{1-4}$ Fetal cardiac dysfunction has also been shown to be an early sign of compromise in fetal growth restriction ${ }^{5}$ and these cardiac changes may persist after delivery

received

July 31, 2019

accepted

August 6, 2019 and potentially contribute to long-term adult cardiovascular disease. $^{6}$

The evaluation of fetal cardiac function by ultrasound has been extensively studied, and several modalities currently exist for the assessment of the fetal heart. Subjective assessment of cardiac contractility is typically followed by objective evaluation. Systolic function can be measured
Copyright $\odot$ by Thieme Medical Publishers, Inc., 333 Seventh Avenue, New York, NY 10001, USA. Tel: +1(212) 584-4662.
DOI https://doi.org/ 10.1055/s-0039-1697585. ISSN $0735-1631$. 
using M-mode by calculating ejection fraction via axial evaluation of the ventricular diameter, and by longitudinal evaluation of annular plane excursion. Diastolic function can be measured by evaluating annular velocities during the cardiac cycle using tissue Doppler. ${ }^{7}$

Myocardial performance index (MPI) is a measure of global fetal cardiac function. ${ }^{5}$ Its utility was first described by Tei et al in the adult population, ${ }^{8}$ and it has since been applied to fetal cardiac assessment. ${ }^{9,10}$ The MPI is calculated by obtaining measurements of cardiac cycle events using Doppler waveforms. The inflow and outflow of a single ventricle are recorded and time intervals of the cardiac cycle are identified. Isovolumetric contraction time (IVCT) and isovolumetric relaxation time comprise the total isovolumetric time (IVT) and MPI is calculated by dividing the total IVT by the ejection time (ET) of the cardiac cycle $(\mathrm{MPI}=\mathrm{IVT} / \mathrm{ET})$. This measure of cardiac function can be obtained by conventional spectral Doppler, where blood flow velocimetric tracings are used to determine cardiac cycle events. For example, a single tracing of flow across the mitral and aortic valves can be used for calculating MPI for the left ventricle, or separate tracings of flow across the tricuspid and pulmonary valves can be used for calculating MPI of the right ventricle. MPI can also be calculated by applying spectral Doppler imaging to the myocardial tissue, lateral to the atrioventricular valve annuli, ${ }^{11}$ and obtaining waveforms of myocardial velocities, corresponding to the events of the cardiac cycle. This is referred to as tissue Doppler imaging (TDI).

To date, no studies have prospectively compared the feasibility and reproducibility of MPI using conventional spectral Doppler versus TDI in an unselected, high-risk, third trimester population. The aim of this study is therefore to assess the feasibility and reproducibility of MPI measurement of the left and right ventricle using the conventional spectral Doppler and TDI approaches in an unselected highrisk third trimester population. We hypothesize that TDI is a more feasible and reproducible method for MPI measurement in the third trimester of pregnancy.

\section{Materials and Methods}

This was a prospective cross-sectional study completed in the Division of Maternal Fetal Medicine at Eastern Virginia Medical School in Norfolk, Virginia. The institutional review board approved the study (Eastern Virginia Medical School IRB 10-10-EX-0244) and all patients gave written informed consent.

\section{Study Population}

High-risk pregnant women were recruited into the study if they were at least 28 weeks of gestation and had a singleton pregnancy. Gestational age was confirmed in the first trimester in all pregnancies using the American College of Obstetricians and Gynecologists guidelines for pregnancy dating. ${ }^{12}$ High-risk pregnancy for study inclusion was defined by the presence of one or more of the following: pregestational hypertension currently on medication, pregestational diabetes, gestational diabetes controlled with medication, intrauterine growth restriction (defined as sonographic estimated fetal weight of $\leq 10$ th percentile or abdominal circumference $\leq 5$ th percentile), congenital fetal cardiac anomalies, major extracardiac fetal anomalies, or maternal obesity, defined with a BMI of greater than or equal to $30 \mathrm{~kg} / \mathrm{m}^{2}$. Patients were excluded if they had multiple gestations, were low risk by the criteria listed above, or declined to participate.

\section{Ultrasound Examination}

Ultrasound examinations were performed between February and August 2016, using the General Electric Voluson E8 or E10 ultrasound systems (GE Healthcare, Wauwatosa, WI), with a 4 to $8-\mathrm{MHz}$ curvilinear transabdominal transducer. A full fetal echocardiogram was first performed and an attempt was made to obtain conventional spectral and TDI measurements of right and left ventricle MPI on every subject. Conventional spectral and TDI MPI measurements were obtained in the following fashion:

\section{Conventional Spectral Doppler-MPI of Left Ventricle}

An apical or basal five-chamber view of the fetal heart was obtained. A Doppler sample volume size of 2 to $4 \mathrm{~mm}$ was used. ${ }^{13}$ Doppler tracings were obtained by placing the sample volume within the left ventricle between the aortic and mitral valves allowing simultaneous recording of the left ventricular inflow (mitral valve) and outflow (aortic valve). Doppler gain was adjusted to make opening and closing valve clicks of the aortic and mitral valves visible on the Doppler spectrum. Angle of insonation was maintained at less than or equal to 30 degrees to the direction of blood flow to optimize quality of the Doppler tracing (-Fig. 1). Sweep speed was also adjusted to optimize tracing quality. Angle correction was used up to 30 degrees when required. Isovolumetric relaxation time (IVRT), IVCT, and ET were measured using the beginning of the valve click reflection as the landmark for measurement of cardiac cycle intervals. The MPI of left ventricle was then calculated by the formula: (IVRT + IVCT)/ET. ${ }^{13}$

\section{Conventional Spectral Doppler-MPI of Right Ventricle}

Given that the right ventricular inflow and outflow are not in same ultrasound plane, spectral Doppler tracings were obtained from the tricuspid and pulmonary valves separately. Doppler tracing of the tricuspid valve was obtained in a basal or apical four-chamber view and the pulmonary artery Doppler waveform was obtained in the right ventricular outflow tract view. The Doppler sample volume size was kept between 2 and $4 \mathrm{~mm}$ and angle of insonation was maintained at less than or equal to 30 degrees to the direction of blood flow. ${ }^{13}$ Angle correction was used up to 30 degrees when required. Sweep speed was also adjusted to optimize tracing quality. Fetal heart rate was determined for each of the two tracings. Tracings were used to calculate MPI only if the difference in the heart rate was $\leq 5 \mathrm{bpm} .{ }^{7}$ Doppler gain was adjusted so that valve clicks and filling and ejection waves were clearly visible. Pulmonary valve ET was measured using the beginning of the valve click as the landmark for measurement. The total IVT was calculated by subtracting 


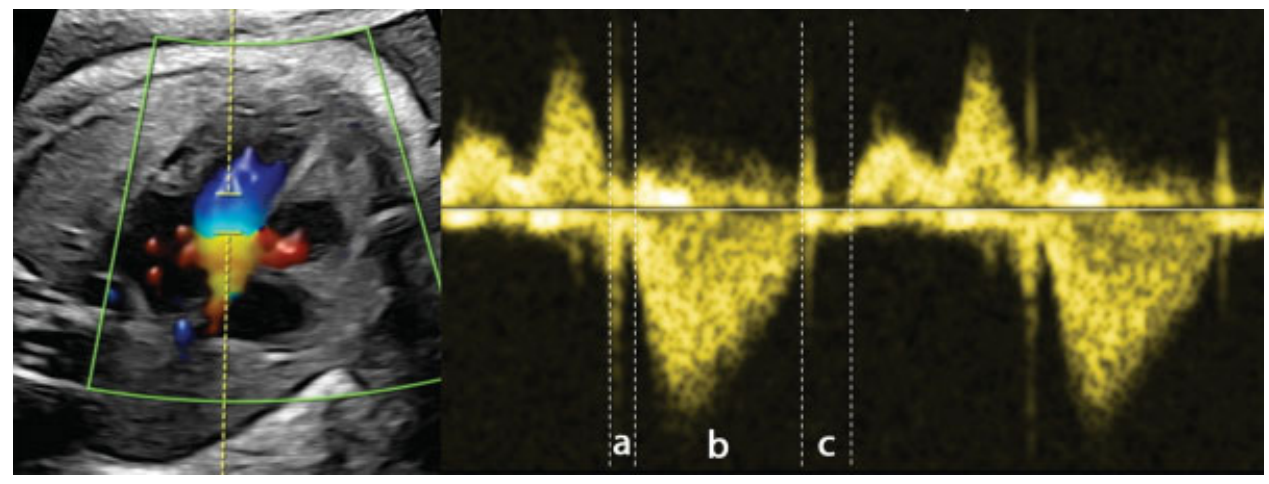

Fig. 1 Conventional spectral Doppler acquisition of MPI of the left ventricle. Doppler gate is placed between the mitral and aortic valves in the five-chamber view. Color Doppler can be applied to assist gate placement. On the resulting tracing, time intervals are shown where a =IVC, $\mathrm{b}=\mathrm{ET}$, and $\mathrm{c}=\mathrm{IVRT}$. ET, ejection time; IVCT, isovolumetric contraction time; IVRT, isovolumetric relaxation time.

the pulmonary valve ET from the time between tricuspid valve filling waves. The MPI of the right ventricle was calculated using the formula IVT/ET ( - Fig. 2).

\section{TDI-MPI of Right and Left Ventricle}

An apical or basal four-chamber view was obtained and the sample Doppler gate was placed over the lateral aspect of the mitral or tricuspid valve annulus. The Doppler sample volume size was kept between 2 and $6 \mathrm{~mm}$ and the angle of insonation was kept at less than 30 degrees with no angle correction applied in keeping with previously published methods. ${ }^{11}$ The wall filter, pulse repetition frequency (PRF), and Doppler gain were adjusted to allow capture of myocardial motion without demonstration of intracardiac blood flow. Sweep speed was adjusted to optimize Doppler tracing. Annular velocity waveforms were captured demonstrating a biphasic filling wave and monophasic ejection wave $\left(\mathrm{ET}^{\prime}\right)$. IVCT' was measured as the interval between the end of the a' wave and the onset of the s' wave. IVRT' was measured as the interval between the end of the $s^{\prime}$ wave and the beginning of the $\mathrm{e}^{\prime}$ wave. $\mathrm{ET}^{\prime}$ was measured from the onset to the ending of the $\mathrm{s}^{\prime}$ wave. Tissue Doppler MPI (MPI') was calculated using formula: $\mathrm{MPI}^{\prime}=\left(\mathrm{IVCT}^{\prime}+\mathrm{IVRT}^{\prime}\right) / \mathrm{ET}^{\prime}$ (-Fig. 3).

MPI measurements were performed on stored images of spectral and tissue Doppler tracings. For each Doppler spectrum (conventional spectral Doppler and TDI) MPI was measured on three separate cardiac cycle waveforms, and the average of the three measurements was used.

Study required criteria for successful completion of each Doppler modality are listed in -Table $\mathbf{1}$.

\section{Reproducibility}

A random sample of 30 patients was chosen from the study population to assess inter and intraobserver variability. The primary investigator (L.P.) re-measured MPI from stored

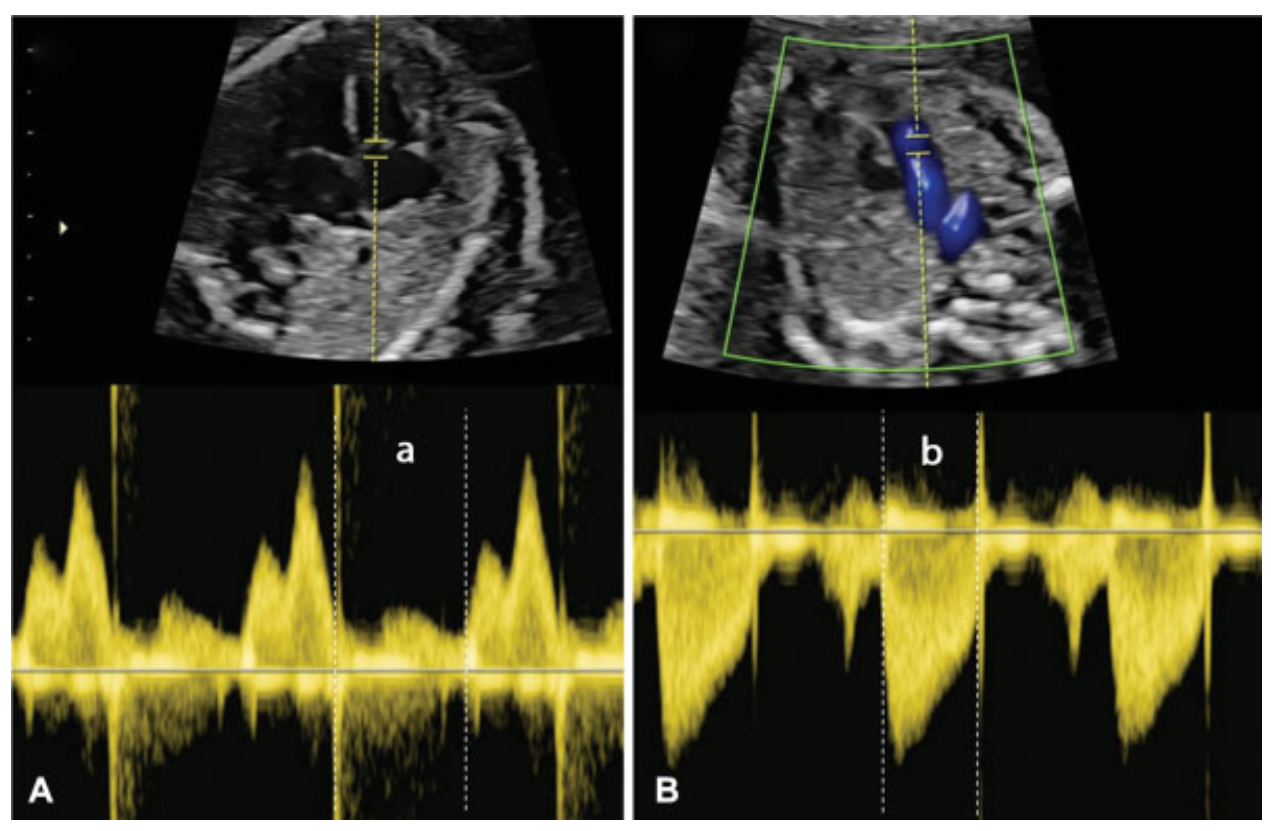

Fig. 2 (A, B) Conventional spectral Doppler acquisition of MPI of the right ventricle. Doppler gate is placed distal to the pulmonary valve and apical to the tricuspid valve. On the resulting tracing, $a=E T$ and $b=$ time between RV filling waves. These time intervals are used to calculate MPI. $E T$, ejection time; MPI, myocardial performance index. 

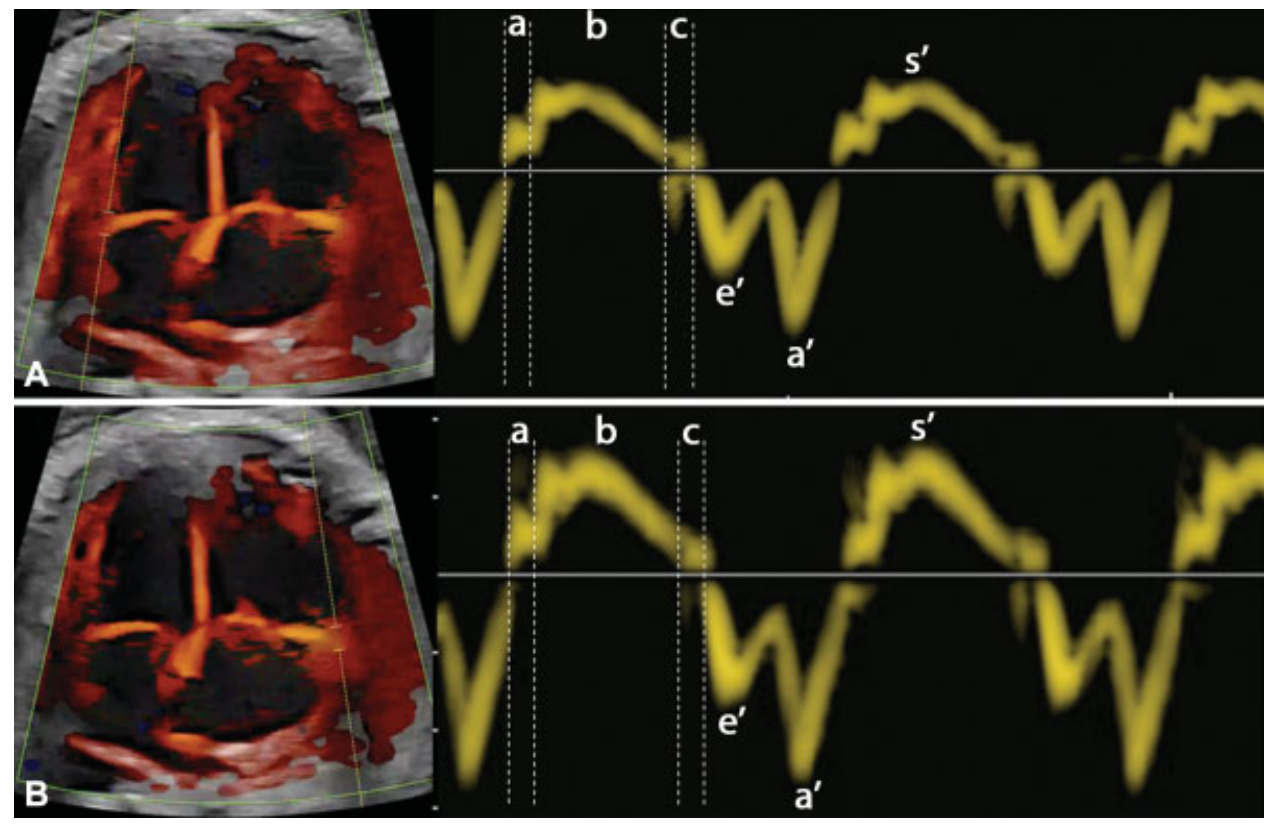

Fig. 3 Spectral tissue Doppler acquisition of MPI lateral to the mitral valve annulus for the left ventricle (A) and the tricuspid valve annulus for the right ventricle (B). Color can be applied to assist in Doppler gate placement (as shown here) but is not required. On the resultant Doppler spectra, time intervals are measured to calculate $\mathrm{MPI}^{\prime}$, where $\mathrm{a}=\mathrm{IVCT}{ }^{\prime}, \mathrm{b}=\mathrm{ET}^{\prime}$, and $\mathrm{c}=\mathrm{IVRT}^{\prime}$. ET', ejection time for TDI; IVCT', isovolumetric contraction time for TDI; IVRT', isovolumetric relaxation time for TDI; $\mathrm{MPI}^{\prime}$, myocardial performance index for TDI. $\mathrm{e}^{\prime}$, early filling wave, $\mathrm{a}^{\prime}$, late filling wave, $\mathrm{s}^{\prime}$, systolic ejection wave.

Table 1 Criteria for successful completion of Doppler techniques

\begin{tabular}{|c|c|c|c|c|c|}
\hline & $\begin{array}{l}\text { Left spectral } \\
\text { MPI }\end{array}$ & $\begin{array}{l}\text { Right spectral } \\
\text { MPI: tricuspid }\end{array}$ & $\begin{array}{l}\text { Right spectral } \\
\text { MPI: pulmonary }\end{array}$ & $\begin{array}{l}\text { Left tissue } \\
\text { Doppler MPI }\end{array}$ & $\begin{array}{l}\text { Right tissue } \\
\text { Doppler MPI }\end{array}$ \\
\hline View & $\begin{array}{l}\text { Five-chamber } \\
\text { view }\end{array}$ & $\begin{array}{l}\text { Apical or basal } \\
\text { four-chamber view }\end{array}$ & $\begin{array}{l}\text { Right ventricular } \\
\text { outflow tract }\end{array}$ & $\begin{array}{l}\text { Apical or basal } \\
\text { four-chamber view }\end{array}$ & $\begin{array}{l}\text { Apical or basal } \\
\text { four-chamber view }\end{array}$ \\
\hline $\begin{array}{l}\text { Sample volume } \\
\text { location }\end{array}$ & $\begin{array}{l}\text { Between mitral } \\
\text { and aortic valves }\end{array}$ & $\begin{array}{l}\text { Distal to } \\
\text { tricuspid valve }\end{array}$ & $\begin{array}{l}\text { Distal to } \\
\text { pulmonary valve }\end{array}$ & $\begin{array}{l}\text { Lateral to mitral } \\
\text { valve annulus }\end{array}$ & $\begin{array}{l}\text { Lateral to tricuspid } \\
\text { valve annulus }\end{array}$ \\
\hline Sample gate size & $2-4 \mathrm{~mm}$ & $2-4 \mathrm{~mm}$ & $2-4 \mathrm{~mm}$ & $2-6 \mathrm{~mm}$ & $2-6 \mathrm{~mm}$ \\
\hline $\begin{array}{l}\text { Angle of } \\
\text { insonation }\end{array}$ & $\begin{array}{l}<30 \text { degrees } \\
\text { to blood flow }\end{array}$ & $\begin{array}{l}<30 \text { degrees to } \\
\text { blood flow }\end{array}$ & $\begin{array}{l}<30 \text { degrees to } \\
\text { blood flow }\end{array}$ & $\begin{array}{l}<30 \text { degrees } \\
\text { to annulus }\end{array}$ & $\begin{array}{l}<30 \text { degrees } \\
\text { to annulus }\end{array}$ \\
\hline $\begin{array}{l}\text { Angle correction } \\
\text { used }\end{array}$ & $<30$ degrees & $<30$ degrees & $<30$ degrees & No & No \\
\hline \multirow[t]{2}{*}{$\begin{array}{l}\text { Tracing } \\
\text { characteristics }\end{array}$} & \multirow[t]{2}{*}{$\begin{array}{l}\text { Valve clicks } \\
\text { well seen }\end{array}$} & $\begin{array}{l}\text { Valve clicks and } \\
\text { interval between } \\
\text { RV filling well seen }\end{array}$ & $\begin{array}{l}\text { Valve clicks } \\
\text { well seen }\end{array}$ & \multirow[t]{2}{*}{$\begin{array}{l}\text { Cardiac cycle } \\
\text { intervals visible }\end{array}$} & \multirow[t]{2}{*}{$\begin{array}{l}\text { Cardiac cycle } \\
\text { intervals visible }\end{array}$} \\
\hline & & FHR within 5 bpm & & & \\
\hline
\end{tabular}

Abbreviations: FHR, fetal heart rate; RV, right ventricle.

conventional spectral and Tissue Doppler waveforms at least 1 week from the time of original acquisition, using the study measurement criteria. These data were used to calculate intraobserver variability. A second investigator (E.S.) independently measured the conventional spectral and Tissue Doppler waveforms, and these data were used to calculate interobserver variability.

\section{Safety}

Attempt was made to limit total ultrasound exposure time to less than 20 minutes in compliance with the As Low As Reasonably Achievable principle. ${ }^{14}$ Doppler imaging was applied in bursts of 15 seconds or less with a total Doppler exposure time of less than 2 minutes.

\section{Outcomes}

The study primary outcome was the rate of successful completion of left and right ventricular MPI measurement using conventional spectral and tissue Doppler approaches. Secondary outcomes included the rate of successful completion of left and right ventricular MPI in a subset of obese pregnant women and overall MPI intra and interobserver agreement in repeated measurements using conventional spectral and tissue Doppler methods. 


\section{Statistical Analysis}

Continuous variables were reported as mean \pm standard deviation (SD), or median with range depending on the data distribution. Categorical data were expressed using frequencies and percentages. McNemar's test was used to compare proportions. Intraclass correlation coefficients were used to evaluate correlation between repeated measures to assess intra and inter-rater reliability. An intraclass correlation coefficient (ICC) value of 0.75 and above indicates an excellent reliability. Values between 0.60 and 0.74 suggest good reliability, values between 0.40 and 0.59 reflect fair reliability, and those falling below 0.40 suggest poor agreement. ${ }^{15}$ Bland-Altman plots were used as a secondary method to assess measurement reliability. A range of agreement was defined as bias \pm 2 SD also known as the $95 \%$ limit of agreements; a low bias value reflects adequate observer reliability. ${ }^{16}$ Pearson correlation coefficient was used to compare correlation of numerical MPI values between modalities and laterality. A p-value of less than 0.05 and a $95 \%$ confidence interval not crossing 1 was considered significant. All analyses were conducted using SAS v9.4 (SAS Institute, Cary, NC) and Microsoft Excel (Redmond, WA).

\section{Results}

Seventy-nine pregnancies met the study inclusion criteria and were enrolled into the study. Patients' demographics and clinical characteristics are presented in - Table 2.

Left ventricular conventional spectral Doppler MPI was completed in 44/79 subjects (55.7\%). Factors contributing to failure included poor tracing quality with inability to identify valve clicks due to ultrasound shadowing $(29 / 35,82.9 \%)$ and suboptimal fetal positioning leading to failure to obtain adequate apical or basal or outflow tract view (26/35, 74.3\%). Right ventricular conventional spectral Doppler MPI was completed in $42 / 79$ subjects (53.2\%). Factors contributing to failure were discrepancy in fetal heart rate between tricuspid and pulmonary valve tracings of $>5 \mathrm{bpm}(28 / 37,75.7 \%)$, acoustic shadowing $(29 / 37,78.4 \%)$, and inadequate fetal positioning leading to failure to obtain adequate apical, basal, or outflow tract view (28/37, 75.7\%). Pearson correlation coefficient comparing left ventricle (LV) and right ventricle (RV) spectral Doppler MPI values was 0.56 .

Left ventricular tissue Doppler MPI was completed in 62/ 79 subjects (78.4\%). Factors contributing to failure were acoustic shadowing $(15 / 17,88.2 \%)$ and inability to insonate at less than 30 degrees due to fetal position (basal view not obtained in $12 / 17,70.6 \%$ and apical view not obtained in $7 /$ 17, 41.2\%). Right ventricular tissue Doppler MPI was completed in $67 / 79$ subjects (84.8\%). Factors contributing to failure of completion were acoustic shadowing (9/12, 75\%), and inability to insonate at less than 30 degrees due to fetal position (basal not obtained in 10/12, 83.3\%, apical not obtained in $4 / 12,33.3 \%$ ). Pearson correlation coefficient comparing LV and RV tissue Doppler MPI values was 0.22 .

Tissue Doppler was completed more frequently than conventional spectral Doppler for the left ventricle (78.4 vs. $55.7 \%, p<0.01)$ and the right ventricle ( 84.8 vs. $53.2 \%$, $p<0.01$ ). These values were statistically significant ( - Fig. 4 ).
Table 2 Maternal and pregnancy characteristics of study participants

\begin{tabular}{|c|c|}
\hline & Total cohort \\
\hline Characteristics & $n=79$ \\
\hline Age (y) & $28.5 \pm 6.4$ \\
\hline Gravity & $2(0-9)$ \\
\hline Parity & $1(1-6)$ \\
\hline Gestational age & 33 wk $6 \mathrm{~d} \pm 23.9 \mathrm{~d}$ \\
\hline \multicolumn{2}{|l|}{ Race } \\
\hline African American & $45(57)$ \\
\hline White & $32(39.2)$ \\
\hline Asian & $1(1.3)$ \\
\hline Hispanic & $1(1.3)$ \\
\hline Other & $1(1.3)$ \\
\hline BMI $\left(\mathrm{kg} / \mathrm{m}^{2}\right)$ & $34.7(19.5-70.6)$ \\
\hline Normal weight $(<30)$ & $27(34)$ \\
\hline Obese $(\geq 30)$ & $50(63.3)$ \\
\hline Obesity Class I (30-34.9) & $19(24.1)$ \\
\hline Obesity Class II (35-39.9) & $12(15.2)$ \\
\hline Obesity Class III ( $\geq 40)$ & $19(24.1)$ \\
\hline \multicolumn{2}{|l|}{ Pregnancy complication } \\
\hline Obesity & $50(63.3)$ \\
\hline IUGR & $32(40.5)$ \\
\hline Fetal cardiac anomaly ${ }^{a}$ & $17(21.5)$ \\
\hline Diabetes & $12(17.7)$ \\
\hline Chronic hypertension & $5(6.3)$ \\
\hline Fetal extracardiac ${ }^{\mathrm{b}}$ anomaly & $4(5.1)$ \\
\hline Fetal anemia & $1(1.3)$ \\
\hline
\end{tabular}

${ }^{a}$ Fetal cardiac defects included: atrial septal defect, ventricular septal defect, tricuspid valve dysplasia with severe regurgitation, coarctation of the aorta, Tetralogy of Fallot, myocardial hypetrophy.

betal extracardiac anomalies included: gastroschisis, omphalocele, large facial vascular mass, renal anomalies, and spinal anomalies.

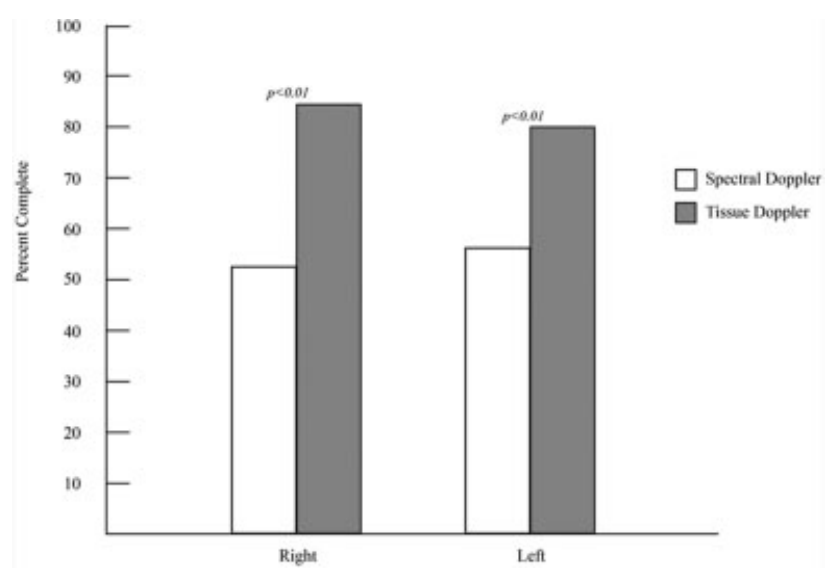

Fig. 4 Tissue Doppler was completed more frequently than spectral Doppler for the right ventricle $(84.8$ vs. $53.2 \%, p<0.01)$ and for the left ventricle $(78.4$ vs. $55.7 \%, p<0.01)$. This difference was statistically significant. 


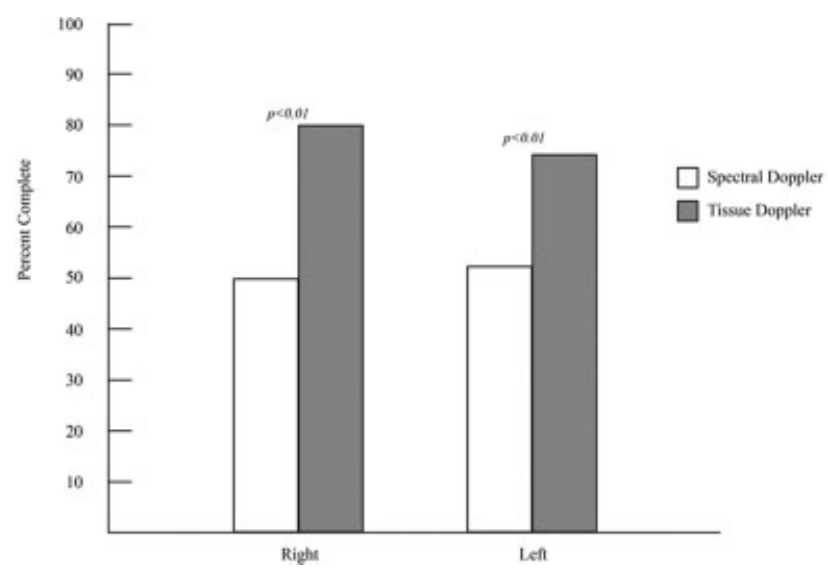

Fig. 5 Tissue Doppler was completed more frequently than spectral Doppler in the obese population for the right ventricle ( 80 vs. $50 \%$, $p<0.01$ ) and for the left ventricle (74 vs. $52 \%, p<0.01$ ). This difference was statistically significant.

Fifty obese subjects, defined with BMI $\geq 30 \mathrm{~kg} / \mathrm{m}^{2}$, were identified for subanalysis. Left ventricular conventional spectral Doppler was completed in 26/50 subjects (52\%). Right ventricular conventional spectral Doppler was completed in 25/50 subjects (50\%). Left ventricular tissue Doppler was completed in $37 / 50$ subjects (74\%), and right ventricular tissue Doppler was completed in 40/50 subjects (80\%). Tissue Doppler was completed more frequently than conventional spectral Doppler for the left ventricle ( 74 vs. $52 \%, p<0.01$ ) and right ventricle ( 80 vs. $50 \%, p<0.01$ ) in the obese population (-Fig. 5 ).

Pearson correlation coefficient comparing RV conventional spectral and tissue Doppler MPI values was 0.06. Pearson correlation coefficient comparing LV spectral and tissue Doppler values was 0.02 .

\section{Intra and Interobserver Variability}

The intra and interobserver variability was evaluated using ICCs. Intraobserver ICC for RV spectral Doppler was 0.728 (95\% CI 0.477-0.869), for RV tissue Doppler was 0.897 (95\% CI 0.782-0.953), for LV spectral Doppler was 0.767 (95\% CI 0.529-0.893), and for LV tissue Doppler was 0.895 (95\% CI 0.775-0.953). Strong interobserver ICC for right and left tissue Doppler was noted with values of 0.926 (95\% Cl 0.852-0.964) and 0.854 (95\% CI 0.719-0.927). Interobserver ICC of RV spectral Doppler was 0.805 (95\% CI 0.628-0.902). Interobserver ICC for LV spectral Doppler was low at 0.224 , but this finding was not statistically significant (95\% CI -0.123-0.529) (- Table 3).

Bland-Altman analysis showed low bias for all modalities ranging from 0.002 to 0.066 . The majority of measurements fell between the $95 \%$ limits of agreement suggesting satisfactory consistency between measures ( - Table 4 ).

\section{Discussion}

This study found that MPI completion rates using TDI were significantly higher than MPI completion rates using spectral Doppler blood flow approach in a high-risk third trimester pregnancy population. This trend also reached statistical
Table 3 Doppler modality: intraobserver and interobserver variability between repeated measures

\begin{tabular}{|l|l|l|}
\hline $\begin{array}{l}\text { Doppler } \\
\text { technique }\end{array}$ & $\begin{array}{l}\text { Intraobserver } \\
\text { ICC }\end{array}$ & $\begin{array}{l}\text { Interobserver } \\
\text { ICC }\end{array}$ \\
\hline $\begin{array}{l}\text { Right spectral } \\
\text { Doppler MPI }\end{array}$ & $\begin{array}{l}0.728 \\
(0.477-0.869)\end{array}$ & $\begin{array}{l}0.805 \\
(0.628-0.902)\end{array}$ \\
\hline Right tissue & 0.897 & 0.926 \\
Doppler MPI & $(0.782-0.953)$ & $(0.854-0.964)$ \\
\hline Left spectral & 0.767 & 0.224 \\
Doppler MPI & $(0.529-0.893$ & $(-0.132-0.529)$ \\
\hline Left tissue & 0.895 & 0.854 \\
Doppler MPI & $(0.775-0.953)$ & $(0.719-0.927)$ \\
\hline
\end{tabular}

Abbreviations: ICC, interclass correlation coefficient; MPI, myocardial performance index.

Note: Data are given as interclass correlation coefficient (95\% confidence interval).

Table 4 Doppler modality bias

\begin{tabular}{|l|l|l|}
\hline $\begin{array}{l}\text { Doppler } \\
\text { technique }\end{array}$ & $\begin{array}{l}\text { Intraobserver } \\
\text { Bland-Altman bias }\end{array}$ & $\begin{array}{l}\text { Interobserver } \\
\text { Bland-Altman bias }\end{array}$ \\
\hline $\begin{array}{l}\text { Right spectral } \\
\text { Doppler MPI }\end{array}$ & $\begin{array}{l}-0.066 \\
(-0.239-0.107)\end{array}$ & $\begin{array}{l}-0.002 \\
(-0.176-0.173)\end{array}$ \\
\hline Right tissue & -0.009 & 0.009 \\
Doppler MPI & $(-0.118-0.100)$ & $(-0.083-0.100)$ \\
\hline Left spectral & -0.041 & -0.025 \\
Doppler MPI & $(-0.160-0.077)$ & $(-0.255-0.205)$ \\
\hline Left tissue & -0.011 & -0.029 \\
Doppler MPI & $(-0.143-0.122)$ & $(-0.186-0.128)$ \\
\hline
\end{tabular}

Abbreviations: MPI, myocardial performance index.

Note: Data are given as bias (95\% limit of agreement LOA).

significance in the subanalysis of obese subjects. Intra and interobserver variability was lower for TDI, suggesting that it may be a more reliable method with which to evaluate global fetal cardiac function by MPI.

Our study findings are in agreement with prior studies that have compared conventional spectral Doppler and TDI for the determination of fetal MPI. Bui et al retrospectively obtained conventional spectral and tissue Doppler measurements of the right ventricle in normal fetuses and in fetuses of diabetic mothers between 17 and 23 weeks. They determined that tissue Doppler was more sensitive and precise in the detection of subtle changes in cardiac function. They also noted a similar trend in decreased inter and intraobserver variability with tissue Doppler. ${ }^{17}$ These findings are similar to the findings in our prospective third trimester cohort.

Acharya et al retrospectively compared conventional spectral Doppler and TDI MPI values from the left and right ventricle in fetuses at 18 to 41 weeks to assess correlation and completion rates. They reported higher MPI completion rates for all modalities (81-91\%) with a trend toward higher completion rates by conventional spectral Doppler. ${ }^{18}$ This difference in trend is likely due to the retrospective nature of their study, selecting only those cases on which MPI was attempted. Also, maternal characteristics were not reported. 
Our finding of a slightly lower overall completion rate is likely due to our prospective study design including unselected highrisk pregnant women in a clinical setting, with a high proportion of obese patients included. Acharya et al also looked at the correlation coefficients comparing conventional spectral and TDI MPI values for the right and left ventricles. Their data did not suggest strong correlation, or ability to interchange the actual MPI values. ${ }^{18}$ Similar findings were noted in our study, suggesting poor agreement when comparing MPI values between the RV and LV within modalities. This can be explained by the fact that conventional spectral and TDI are evaluating different measurements (blood flow vs. myocardial motion). In addition, the physiology of the right and left ventricles in the fetus differs significantly. Applicable to both of these comparisons, trends in the change in MPI in the setting of disease states may be the same, but numerical values may not. For this reason, specific reference ranges for each modality and for each ventricle are important.

Conventional spectral Doppler, the traditional modality originally applied to MPI calculation, ${ }^{9}$ presents some challenges. Discrepancy has been seen in left ventricular MPI reference ranges published due to inconsistencies in methods of measuring time intervals. ${ }^{19}$ Welsh et al also showed that even expert varies greatly when classifying the suitability of a tracing for evaluation. ${ }^{20}$ This proven variability in determining adequacy for evaluation may explain our unexpectedly low correlation coefficient with reference to the interobserver variability of left ventricular spectral Doppler MPI. The use of automated MPI calculation programs has also been shown to improve reproducibility when compared with manual calculation. Their use, while limited by availability, decreases interobserver variability. ${ }^{20}$ Furthermore, the use of separate tricuspid and pulmonary Doppler tracings for evaluation of right ventricular MPI presents inherent technical difficulty in acquisition of usable waveforms. Variation in fetal heart rate greater than $5 \mathrm{bpm}$ between the tricuspid and pulmonary Doppler tracings renders them inadequate for evaluation. The requirement of two distinct Doppler spectra for blood flow MPI of the right ventricle and the similarity in the fetal heart rate renders this approach less feasible, especially with increased fetal heart rate variability in the third trimester. Programs for automation of the MPI measurement for the right ventricle are also being developed. ${ }^{21}$

The direct assessment of cardiac time intervals using TDI overcomes these challenges. Tissue Doppler has previously been validated for use in the fetus and allows direct evaluation of myocardial motion during the cardiac cycle. ${ }^{11}$ It has been shown to be technically feasible ${ }^{22}$ with good reproducibility. ${ }^{23}$ Spectral TDI can be obtained on conventional obstetric ultrasound equipment by changing gain, PRF, and wall motion settings. This obviates the need for specialized cardiac ultrasound equipment or sophisticated offline software analysis. Placement of a single Doppler gate in acquisition of right ventricular TDI for MPI measurement circumvents the need for separate tracings of ventricular inflow and outflow with similar fetal heart rate. Fetal position and ultrasound beam penetration are some limiting factors in the use of this modality. Traditionally, angle correction has not been used for the acquisition of $\mathrm{TDI}^{7}$ so that velocities can accurately be obtained from the tracing. Since MPI only focuses on time intervals and not velocities, the use of angle correction might be considered. More investigation is warranted regarding this issue. Due to the ability to apply this modality in a wide range of clinical circumstances, training for the use of TDI should be provided to physicians and sonographers involved in fetal cardiovascular assessment in high-risk pregnancies.

Increasing percentages of the United States population are classified as obese $\mathrm{e}^{24}$ and over half of the pregnant women in the United States were overweight or obese as of $2010 .^{25} \mathrm{An}$ association between obesity and pregnancy complications exists. ${ }^{26}$ Some of these complications may potentially impact fetal cardiac structure and function. ${ }^{27}$ It has also been shown that obesity itself is a risk factor for changes in fetal cardiac function ${ }^{28}$ with increased isovolumetric times and $\mathrm{MPI}^{29}$ compared with fetuses of normal weight mothers. Given these factors it is important to have a reliable method of evaluating fetal cardiac function in pregnancies complicated by maternal obesity. Our study supports the use of tissue Doppler for MPI assessment in the obese gravida.

The limitations of this study include that a single author with training in fetal cardiac function (L.P.) was the sole collector of all research examinations. The second operator assessing reliability (E.S.) also has extensive experience in fetal cardiac function. Working within an ultrasound unit with such experience in fetal cardiac assessment may limit the applicability to centers with less training or experience.

The strengths of this study include the prospective nature of our data collection with prestudy defined criteria for acceptance of Doppler tracings for evaluation. This limits the subjectivity of our data interpretation. Our study high-risk population was also diverse in maternal and fetal characteristics and ultrasound imaging for data acquisition was performed in a busy high-risk ultrasound unit using standard obstetric ultrasound equipment, showing that these studies can be completed in most practices with the appropriate training. Our study was limited to the third trimester, the time in which serial fetal monitoring and management decisions are being made in the majority of high-risk pregnancies. This shows that TDI can be applied to a wide range of clinical scenarios and maternal characteristics. More research is needed regarding correlation of TDI MPI measurements and neonatal outcomes to create guidelines that facilitate management decision.

In conclusion, our data show that MPI obtained by tissue Doppler has a higher completion rate and lower inter and intraobserver variability than conventional spectral Doppler MPI in a high-risk third trimester cohort. This modality should be considered for the assessment and monitoring of fetal cardiac function in this population.

Conflict of Interest

None declared.

\section{Acknowledgments}

The authors would like to thank the staff of the ultrasound unit at Eastern Virginia Medical School for their support and assistance with patient recruitment. 


\section{References}

1 Balli S, Pac FA, Ece İ, Oflaz MB, Kibar AE, Kandemir Ö. Assessment of cardiac functions in fetuses of gestational diabetic mothers. Pediatr Cardiol 2014;35(01):30-37

2 Bhorat IE, Bagratee JS, Reddy T. Assessment of fetal myocardial performance in severe early onset pre-eclampsia (EO-PET) with and without intrauterine growth restriction across deteriorating stages of placental vascular resistance and links to adverse outcomes. Eur J Obstet Gynecol Reprod Biol 2017;210:325-333

3 Fishman SG, Pelaez LM, Baergen RN, Carroll SJ. Parvovirus-mediated fetal cardiomyopathy with atrioventricular nodal disease. Pediatr Cardiol 2011;32(01):84-86

4 Huhta JC. Guidelines for the evaluation of heart failure in the fetus with or without hydrops. Pediatr Cardiol 2004;25(03):274-286

5 Comas M, Crispi F, Cruz-Martinez R, Figueras F, Gratacos E. Tissue Doppler echocardiographic markers of cardiac dysfunction in small-for-gestational age fetuses. Am J Obstet Gynecol 2011; 205(01):57.e1-57.e6

6 Crispi F, Bijnens B, Figueras F, et al. Fetal growth restriction results in remodeled and less efficient hearts in children. Circulation 2010;121(22):2427-2436

7 Crispi F, Gratacós E. Fetal cardiac function: technical considerations and potential research and clinical applications. Fetal Diagn Ther 2012;32(1-2):47-64

8 Tei C, Ling LH, Hodge DO, et al. New index of combined systolic and diastolic myocardial performance: a simple and reproducible measure of cardiac function-a study in normals and dilated cardiomyopathy. JCardiol 1995;26(06):357-366

9 Tsutsumi T, Ishii M, Eto G, Hota M, Kato H. Serial evaluation for myocardial performance in fetuses and neonates using a new Doppler index. Pediatr Int 1999;41(06):722-727

10 Eidem BW, Edwards JM, Cetta F. Quantitative assessment of fetal ventricular function: establishing normal values of the myocardial performance index in the fetus. Echocardiography 2001;18(01):9-13

11 Comas M, Crispi F. Assessment of fetal cardiac function using tissue Doppler techniques. Fetal Diagn Ther 2012;32(1-2):30-38

12 Committee opinion no 611: method for estimating due date. Obstet Gynecol 2014;124(04):863-866

13 Hernandez-Andrade E, López-Tenorio J, Figueroa-Diesel H, et al. A modified myocardial performance (Tei) index based on the use of valve clicks improves reproducibility of fetal left cardiac function assessment. Ultrasound Obstet Gynecol 2005;26(03):227-232

14 Fowlkes JB; Bioeffects Committee of the American Institute of Ultrasound in Medicine. American Institute of Ultrasound in Medicine consensus report on potential bioeffects of diagnostic ultrasound: executive summary. JUltrasound Med 2008;27(04): 503-515

15 Shrout PE, Fleiss JL. Intraclass correlations: uses in assessing rater reliability. Psychol Bull 1979;86(02):420-428
16 Bland JM, Altman DG. Statistical methods for assessing agreement between two methods of clinical measurement. Lancet 1986; 1 (8476):307-310

17 Bui YK, Kipps AK, Brook MM, Moon-Grady AJ. Tissue Doppler is more sensitive and reproducible than spectral pulsed-wave Doppler for fetal right ventricle myocardial performance index determination in normal and diabetic pregnancies. JAm Soc Echocardiogr 2013;26(05):507-514

18 Acharya G, Pavlovic M, Ewing L, Nollmann D, Leshko J, Huhta JC. Comparison between pulsed-wave Doppler- and tissue Dopplerderived Tei indices in fetuses with and without congenital heart disease. Ultrasound Obstet Gynecol 2008;31(04):406-411

19 Cruz-Martínez R, Figueras F, Bennasar M, et al. Normal reference ranges from 11 to 41 weeks' gestation of fetal left modified myocardial performance index by conventional Doppler with the use of stringent criteria for delimitation of the time periods. Fetal Diagn Ther 2012;32(1-2):79-86

20 Welsh AW, Maheshwari P, Wang J, et al. Evaluation of an automated fetal myocardial performance index. Ultrasound Obstet Gynecol 2016;48(04):496-503

21 Wang J, Henry A, Welsh AW, Redmond SJ. Automated cardiac time interval measurement for modified myocardial performance index calculation of right ventricle. Conf Proc IEEE Eng Med Biol Soc 2015;2015:7288-7291

22 Harada K, Tsuda A, Orino T, Tanaka T, Takada G. Tissue Doppler imaging in the normal fetus. Int J Cardiol 1999;71(03):227-234

23 Chan LY, Fok WY, Wong JT, Yu CM, Leung TN, Lau TK. Reference charts of gestation-specific tissue Doppler imaging indices of systolic and diastolic functions in the normal fetal heart. Am Heart J 2005;150(04):750-755

24 Data Briefs-Number 219-November 2015Centers for Disease Control Web site. Available at: https://www.cdc.gov/nchs/products /databriefs/db219.htm. Accessed May 13, 2017

25 Flegal KM, Carroll MD, Kit BK, Ogden CL. Prevalence of obesity and trends in the distribution of body mass index among US adults, 1999-2010. JAMA 2012;307(05):491-497

26 Stothard KJ, Tennant PW, Bell R, Rankin J. Maternal overweight and obesity and the risk of congenital anomalies: a systematic review and meta-analysis. JAMA 2009;301(06):636650

27 Watkins ML, Rasmussen SA, Honein MA, Botto LD, Moore CA. Maternal obesity and risk for birth defects. Pediatrics 2003;111 (5 Pt 2):1152-1158

28 Ingul CB, Lorås L, Tegnander E, Eik-Nes SH, Brantberg A. Maternal obesity affects fetal myocardial function as early as in the first trimester. Ultrasound Obstet Gynecol 2016;47(04):433-442

29 Ece I, Uner A, Balli S, Kibar AE, Oflaz MB, Kurdoglu M. The effects of pre-pregnancy obesity on fetal cardiac functions. Pediatr Cardiol 2014;35(05):838-843 